American Journal of Applied Sciences 1 (4): 332-337, 2004

ISSN 1546-9239

(C) Science Publications, 2004

\title{
The Effect of Socioeconomic and Demographic Factors on Contraceptive Use and Induced Abortion in Turkey
}

\author{
Ozlem Alpu and Gunseli Kurt \\ Department of Statistics, Osmangazi University, Turkey
}

\begin{abstract}
The aim of the study was to estimate the parameters of the heteroscedastic bivariate Probit model established for the induced abortion and the contraceptive use by using socioeconomic and demographic factors and their effects by eliminating the observed heteroscedasticity. Using a heteroscedastic bivariate Probit model and Turkish Demographic and Health Survey (1998) data on married women aged 15 through 49 years, we estimated the probabilities of their having an induced abortion, if induced abortion have, of their using contraceptive methods. The results of the research show that induced abortion is perceived and used as a contraceptive method among the women in Turkey. This shows that it is the correct way to examine those two variables, induced abortion and contraceptive use, together.
\end{abstract}

Key words: Bivariate Probit Model, Heteroscedasticity, Contraceptive Use, Induced Abortion

\section{INTRODUCTION}

In our society, there is excessive fertility and thus, rapid population increase. Excessive fertility negatively affects both the mother's and the infant's health and rapid population increase slows down the speed of development and decreases the share of the investments in education, health and production. Family planning methods have a large share in reducing the excessive fertility rate.

Family planning services and health education are quite important. If women can protect themselves against pregnancy using one of the modern methods, undesired pregnancies and rapid population increase can be hindered. In a research (TNSA-98) ${ }^{[1]}$, it has been reported that $19 \%$ of the births which have been occurring in the last five years are undesired and $11 \%$ of them are unplanned pregnancies. In this case, women may face with abortions and sometimes may endanger their health. Therefore, the spread of using family planning services and modern methods will both decrease and prevent the undesired pregnancies and induced abortions.

In cases where family planning services are not available or enough and other psycho-social factors hinder the use of such methods, women may go towards inducing abortions. Besides, because of the failure of the family planning methods that are used, undesired pregnancies may occur, which cause them to have induced abortion.

Within the health criteria, miscarriages and stillbirths have a special importance. Stillbirths and miscarriages are important indicators in evaluating mother's health. However, as one of the aims of family planning is to prevent undesired pregnancies, induced abortions have a special importance with regard to family planning services.
Individual reproduction choices have national and global consequences so that a nation can determine its ratio of fertility. It is natural for those interested in family planning and reproduction health how the use of contraceptive methods, their efficiency and the spread of miscarriages affect the total fertility ratio of a nation.

Turkey is one of the rare countries where induced abortions are legally allowed up to ten weeks' time of pregnancy. Though the right to have induced abortion is freely used by many women, the social characteristics of the women who prefer to induce abortions instead of family planning services are noteworthy and the fact that the previous habits of contraceptive use of those women are known is an interesting research subject.

Therefore, in this study, the aim was to determine what the socioeconomic and demographic factors affecting the contraceptive use and induced abortion are and what the level of the their marginal effects are. The bivariate Probit model given below is used to realize this aim.

\section{MATERIALS AND METHODS}

The distribution of the error terms of bivariate probit model for binary outcomes has a bivariate standard normal distribution. In addition, it is assumed that the error terms are related with each other ${ }^{[2]}$. Then the bivariate probit model for binary outcomes jointly estimates probit equations in correlated error (disturbance) terms ${ }^{[3]}$.

The specification of this model is:

$\left.\begin{array}{l}y_{1}^{*}=x_{1}^{\prime} \beta_{1}+\varepsilon_{1} \\ y_{2}^{*}=x_{2}^{\prime} \beta_{2}+\varepsilon_{2}\end{array}\right\}\left[\varepsilon_{1}, \varepsilon_{2}\right] \sim \phi_{2}(0,0,1,1, \rho)$

where, $\mathrm{x}_{1}$ and $\mathrm{x}_{2}$ are vectors of independent variables, $\beta_{1}$ and $\beta_{2}$ are vectors of parameters to be estimated, $\varepsilon_{1}$ 
and $\varepsilon_{2}$ are vectors of error terms, $\rho$ is the coefficient of correlation between $\varepsilon_{1}$ and $\varepsilon_{2}$ and dependent (latent) variables $\mathrm{y}_{1}^{*}$ and $\mathrm{y}_{2}^{*}$ are only observed as dichotomous variables $\mathrm{y}_{1}$ and $\mathrm{y}_{2}$, defined as ${ }^{[4]}$ :

$y_{1}=\left\{\begin{array}{lc}1 & \text { if } y_{1}^{*} \geq 0 \\ 0 & \text { otherwish }\end{array}\right.$ and $y_{2}=\left\{\begin{array}{lc}1 & \text { if } y_{2}^{*} \geq 0 \\ 0 & \text { otherwish }\end{array}\right.$

The probability of the occurrence of any level of the two dependent variables (e.g. $P\left(y_{1}=1, y_{2}=2\right)$ ) can be computed with the bivariate normal c.d.f. Since those two models' error terms can be correlated with each other. $\mathrm{P}\left(\mathrm{y}_{1}=1, \mathrm{y}_{2}=1\right)$ for $\mathrm{i}$. The subject is:

$\left.\left.\mathrm{P}\left(\mathrm{y}_{1, \mathrm{i}}=1, \mathrm{y}_{2, \mathrm{i}}=1\right)=\mathrm{P}\left(\mathrm{y}_{1, \mathrm{i}}^{*}\right\rangle 0, \mathrm{y}_{2, \mathrm{i}}^{*}\right\rangle 0, \rho\right)$

$=\phi_{2}\left(\mathrm{x}_{1, i}^{\prime} \beta_{1}, \mathrm{x}_{2, \mathrm{i}}^{\prime} \beta_{2} ; \rho\right)$

$=\int_{-x_{1}^{\prime} \beta_{1}-x_{2}^{\prime} \beta_{2}}^{\infty} \int_{1, i}^{\infty} \phi\left(\varepsilon_{2, i} ; \rho\right) d \varepsilon_{2, i} \cdot d \varepsilon_{1, i}$

The model given in Eq. (3) is called bivariate probit model ${ }^{[2]}$.

The bivariate probit model has four possible outcomes of the joint binary decisions and they are $\left(\mathrm{y}_{1}\right.$ $\left.=1, \mathrm{y}_{2}=1\right),\left(\mathrm{y}_{1}=1, \mathrm{y}_{2}=0\right),\left(\mathrm{y}_{1}=0, \mathrm{y}_{2}=1\right)$ and $\left(\mathrm{y}_{1}=0\right.$, $\mathrm{y}_{2}=0$ ). The corresponding probabilities for the four possible outcomes are:

$$
\begin{aligned}
& \mathrm{P}_{11}=\mathrm{P}\left(\mathrm{y}_{1, \mathrm{i}}=1, \mathrm{y}_{2, \mathrm{i}}=1 / \mathrm{x}_{1, \mathrm{i}}, \mathrm{x}_{2, \mathrm{i}}\right) \\
& =\phi_{2}\left(\left.\mathrm{x}^{\prime}\right|_{1, \mathrm{i}}, \mathrm{x}_{2, \mathrm{i}}^{\prime} \beta_{2} ; \rho\right) \\
& \mathrm{P}_{10}=\mathrm{P}\left(\mathrm{y}_{1, \mathrm{i}}=1, \mathrm{y}_{2, \mathrm{i}}=0 / \mathrm{x}_{1, \mathrm{i}}, \mathrm{x}_{2, \mathrm{i}}\right)=\phi\left(\mathrm{x}_{1.1}^{\prime} \beta_{1}\right)-\mathrm{P}_{11} \\
& \mathrm{P}_{01}=\mathrm{P}\left(\mathrm{y}_{1, \mathrm{i}}=0, \mathrm{y}_{2, \mathrm{i}}=1 / \mathrm{x}_{1, \mathrm{i}}, \mathrm{x}_{2, \mathrm{i}}\right)=\phi\left(\mathrm{x}_{2 . \mathrm{il}}^{\prime} \beta_{2}\right)-\mathrm{P}_{11} \\
& \mathrm{P}_{00}=\mathrm{P}\left(\mathrm{y}_{1, \mathrm{i}}=0, \mathrm{y}_{2, \mathrm{i}}=0 / \mathrm{x}_{1, \mathrm{i}}, \mathrm{x}_{2, \mathrm{i}}\right) \\
& =1-\phi\left(\mathrm{x}_{1 . \mathrm{i}}^{\prime} \beta_{1}\right)-\phi\left(\mathrm{x}_{2, \mathrm{i}}^{\prime} \beta_{2}\right)+\mathrm{P}_{11}
\end{aligned}
$$

where, $\Phi_{2}$ is c.d.f. Of the bivariate standard normal distribution $^{[5]}$.

The two equations can be estimated consistently by individual single equation probe methods. However, this is inefficient in that it ignores the correlation between the error terms ${ }^{[4]}$.

The parameters of the model can be estimated by maximizing the following likelihood function ${ }^{[4]}$ :

$$
\begin{aligned}
& \mathrm{L}\left(\beta_{1}, \beta_{2} ; \rho\right)=\prod_{\mathrm{i}=1}^{\mathrm{T}} \mathrm{P}^{\left(1-\mathrm{y}_{1, \mathrm{i}}\right)\left(1-\mathrm{y}_{2, \mathrm{i}}\right)} \cdot \mathrm{P}^{\left(1-\mathrm{y}_{1, \mathrm{i}}\right) \cdot \mathrm{y}_{2, \mathrm{i}}} 00 \mathrm{i} \\
& 01 \mathrm{i}
\end{aligned}
$$

It is very important to test the heteroscedasticity in qualitative dependent variable models because this mis-specification leads to inconsistent estimators ${ }^{[6]}$. The error terms in one or both probit equations may be heteroscedastic. In this situation, a plausible choice for the functional form of the heterogeneity is a variation of Harvey's "multiplicative heteroscedasticity" approach. So:

$\sigma^{2} i=\sigma^{2} \exp \left(x_{i}^{\prime} \beta\right) i=1, \ldots T$

where, $x$ is a set of independent variables, $\beta$ is unknown parameters to be estimated. In which $x_{i}=\ln z_{i}^{[7-9]}$. As Godfrey suggests, there is a useful simplification of the Eq. (9). Let $z_{i}^{\prime}=\left[1, x_{i}\right]$ and $\gamma^{\prime}=\left[\ln \sigma^{2}, \beta\right]$. Then we can write the model as simply:

$\sigma^{2} \mathrm{i}=\sigma^{2} \exp \left(\mathrm{x}^{\prime} \mathrm{z}_{\mathrm{i}} \gamma\right)^{2}$

where, $\mathrm{z}$ is a set of independent variables that may or may not coincide $\mathrm{x}, \gamma$ is unknown parameters to be estimated.

The heteroscedastic bivariate probit model is like a standard bivariate probit model except for there is a separate equation to model the error variance or the errors in prediction and ${ }^{[2]}$.

$\varepsilon_{\mathrm{s}} \sim \mathrm{N}\left[0, \exp \left(\mathrm{z}_{\mathrm{s}}^{\prime} \gamma_{\mathrm{s}}\right)^{2}\right], \mathrm{s}=1$ and/or 2

The heteroscedastic bivariate probit model is as follows:

$\mathrm{P}\left(\mathrm{y}_{1}=1, \mathrm{y}_{2}=1\right)=\phi_{2}\left(\frac{\mathrm{x}_{1}^{\prime} \beta_{1}}{\exp \left(\mathrm{z}_{1}^{\prime} \gamma_{1}\right)}, \frac{\mathrm{X}_{2}^{\prime} \beta_{2}}{\exp \left(\mathrm{z}_{1}^{\prime} \gamma_{2}\right)}, \rho * *\right)$

If the error terms are heteroscedastic in the probit model, then the ML estimates of the parameters are inconsistent and covariance matrix estimates are incorrect ${ }^{[10]}$. If the researcher is conscious about the heteroscedasticity, in order to obtain the consistent estimates, the variables that can cause heteroscedasticity must be tested. These variables must be added to variance equation part to be adjusted.

There are three tests for heteroscedasticity in the binary choice framework-Likelihood ratio, Lagrange multiplier and Wald test statistics ${ }^{[2,11]}$.

Once parameter estimates are obtained, a natural next step is to consider the marginal effects of the covariates in the conditional distributions. The marginal effects of the bivariate probit model are examined while studying with a heteroscedastic model. The conditional mean function of the bivariate probit model is ${ }^{[12]}$ : 
Table 1: Description of Socioeconomic and Demographic Variables

\begin{tabular}{|c|c|}
\hline Variable & Level \\
\hline \multirow[t]{3}{*}{ Current age of woman } & 1: $15-18$ \\
\hline & 2: 19-34 \\
\hline & 3: 35-49 \\
\hline \multirow[t]{2}{*}{ Type of place of residence } & 0: Rural \\
\hline & 1: Urban \\
\hline \multirow[t]{5}{*}{ Region } & 1: West \\
\hline & 2: South \\
\hline & 3: Central \\
\hline & 4: North \\
\hline & 5: East \\
\hline \multirow[t]{4}{*}{ Education level of woman/partner } & 0 : No education \\
\hline & 1: Primary \\
\hline & 2: Secondary \\
\hline & 3: Higher \\
\hline Number of living children & $0,1, \ldots, 13$ \\
\hline \multirow[t]{4}{*}{ Current type of employment of woman } & 0: Did not work \\
\hline & 1: Paid employee \\
\hline & 2: self employed \\
\hline & 3: Unpaid worker \\
\hline \multirow[t]{6}{*}{ Total income in the household } & 1: Low level monthly income household; which refers to \\
\hline & the households with an income less than 100 million TL. \\
\hline & 2: Middle level monthly income household; which refers to \\
\hline & $\begin{array}{l}\text { the households with an income between } 100 \text { million and } \\
500 \text { million TL. }\end{array}$ \\
\hline & 3: High level monthly income household; which refers to \\
\hline & the households with an income more than 500 million TL. \\
\hline Woman/Partner insured by health & 0:No \\
\hline Insurance & 1: Yes \\
\hline \multirow[t]{2}{*}{ Knowledge of family planning methods } & 0: Knows no method \\
\hline & 1: Knows any method \\
\hline Woman/Partner's approval of family & 0: Disapproves \\
\hline \multirow[t]{2}{*}{ planning methods } & 1: Approves \\
\hline & 2: Doesn't know \\
\hline \multirow{3}{*}{ Partner's position at work } & 1: Self-employed \\
\hline & 2: Wages /on salary \\
\hline & 3: Unpaid family laborer /other \\
\hline
\end{tabular}

$\mathrm{E}\left[\mathrm{y}_{1} / \mathrm{y}_{2}, \mathrm{x}_{1} \mathrm{x}_{2}, \mathrm{z}_{1}, \mathrm{z}_{2}\right]=\mathrm{P}\left(\mathrm{y}_{1}=1 / \mathrm{y}_{2}, \mathrm{x}_{1}, \mathrm{x}_{2}, \mathrm{z}_{1}, \mathrm{z}_{2}\right)$

$=\frac{\mathrm{P}\left(\mathrm{y}_{1}=1, \mathrm{y}_{2}, \mathrm{x}_{1}, \mathrm{x}_{2} \mathrm{z}_{1}, \mathrm{z}_{2}\right)}{\mathrm{P}\left(\mathrm{y}_{2} / \mathrm{x}_{2}, \mathrm{z}_{2}\right)}$

$=\frac{\phi_{2}\left(\mathrm{a}_{1},\left(2 \mathrm{y}_{2}-1\right) \mathrm{a}_{2},\left(2 \mathrm{y}_{2}-1\right) \rho\right)}{\phi\left(\left(2 \mathrm{y}_{2}-1\right) \mathrm{a}_{2}\right)}$

$=\frac{\phi_{2}\left(\mathrm{a}_{1}, \mathrm{q}_{2} \mathrm{a}_{2}, \mathrm{q}_{2} \rho\right)}{\phi\left(\mathrm{q}_{2} \mathrm{a}_{2}\right)}=\frac{\phi_{2}\left(\mathrm{c}_{1}, \mathrm{c}_{2}, \rho^{*}\right)}{\phi\left(\mathrm{c}_{2}\right)}$

Derivatives of the various functions shown above give the desired marginal effects ${ }^{[12]}$.

By using the theory given above up to now, for the applied study, two dependent variables are taken. The first is the decision of whether or not to have an induced abortion; the second is the decision of whether or not to use any contraceptive methods. These are categorized as:

* In Turkey, married women using any contraceptive methods is coded with 1 and those not using any method is coded with 0

* In Turkey, the event of married women having an induced abortion is coded with 1 and the event of married women not having an induced abortion is coded with $0^{[13]}$.
Contraceptive methods can be used to extend the birth interval and to limit the number of children. Generally, pregnancies result in induced abortion, even though it is not a family planning method, if contraceptive methods are not used, misused or inefficiently used. So it is important that we examine the use of contraceptive methods and induced abortion together.

As the independent variables, socioeconomic and demographic variables are taken and given in Table 1. For this application bivariate probit model for binary outcomes is used.

Data used in this study are taken from 6148 married women in 1998 Turkish Demographic and Health Survey (TDHS-98) that was conducted by the Hacettepe Institute of Population Studies.

\section{RESULTS AND DISCUSSION}

From the test statistics, with the Lagrange multiplier, homoscedasticity is tested (Table 2). According to Table 2, first dependent variable induced abortion in the first index equation is affected by age, total income in the household, education level of partner, knowledge of family planning methods and woman's approval of the family planning. 
Table 2: Heteroscedastic Bivariate Probit Model Results: Effects of Socioeconomic and Demographic factors on the Probability of Induced Abortion and Contraceptive Use among Married Women aged 15-49 years

\begin{tabular}{|c|c|c|c|}
\hline Variable & Coefficient & $\begin{array}{l}\text { Standard } \\
\text { Error }\end{array}$ & Z Statistic \\
\hline & \multicolumn{3}{|c|}{ Index equation for induced abortion (Y1) } \\
\hline Age & $0.56931 * * *$ & 0.10604 & 5.369 \\
\hline Total income in the household & $0.31366 * * *$ & 0.10486 & 2.991 \\
\hline Education level of partner & $0.16423 * *$ & 0.07419 & 2.213 \\
\hline Knowledge of FP methods & $-3.26855 * * *$ & 0.45256 & -7.222 \\
\hline Woman's approval of FP & $-0.50530 * * *$ & 0.17133 & -2.949 \\
\hline \multicolumn{4}{|c|}{ Index equation for contraceptive methods (Y2) } \\
\hline Type of place of residence & $0.07995^{*}$ & 0.04663 & 1.715 \\
\hline Region & $-0.17217 * * *$ & 0.02165 & -7.950 \\
\hline Number of living children & $0.44535^{* * *}$ & 0.04735 & 9.405 \\
\hline $\begin{array}{l}\text { Current type of employment of } \\
\text { woman }\end{array}$ & $.09044 * * *$ & 0.02148 & 4.210 \\
\hline Total income in the household & $0.14452 * * *$ & 0.04071 & 3.549 \\
\hline Partner insured by health insurance & $0.29255 * * *$ & 0.05774 & 5.066 \\
\hline Partner's position at work & \multicolumn{3}{|c|}{ Variance equation for $\mathrm{Y} 1$} \\
\hline Type of place of residence & $0.26208 * * *$ & 0.06357 & 4.122 \\
\hline Region & $-0.07424 * * *$ & 0.01990 & -3.730 \\
\hline Education level of woman & 0.07412 & 0.04729 & 1.567 \\
\hline Number of living children & $0.35042 * * *$ & 0.02787 & 12.570 \\
\hline $\begin{array}{l}\text { Current type of employment of } \\
\text { woman }\end{array}$ & $0.05530 * *$ & 0.02675 & 2.067 \\
\hline Partner insured by health insurance & $0.15052 * *$ & 0.05732 & 2.626 \\
\hline Partner's position at work & 0.01098 & $\begin{array}{l}0.04555 \\
\text { Variance equation for Y2 }\end{array}$ & .241 \\
\hline Age & $0.38064 * * *$ & 0.03407 & 11.169 \\
\hline Education level of woman & $-0.40719 * * *$ & 0.02400 & -16.961 \\
\hline Education level of partner & $-0.20238 * * *$ & 0.02261 & -8.948 \\
\hline Woman's approval of FP & $-0.08936 * * *$ & $\begin{array}{l}0.03306 \\
\text { Disturbance Correlation }\end{array}$ & -2.703 \\
\hline$\hat{\rho} * *$ & $.45023^{* * *}$ & $\begin{array}{l}.02730 \\
\text { Goodness of fit }\end{array}$ & 16.491 \\
\hline
\end{tabular}

Likelihood Ratio Test $=288.562 * * *$

Heteroscedasticity Test

Lagrange Multiplier Test $=682.8533 * * *$

$*=\mathrm{p} \leq 0.10 ; * *=\mathrm{p} \leq 0.05 ; * * *=\mathrm{p} \leq 0.01$

Table 3:Correlation Test Results in the Bivariate Probit Model for Induced Abortion and Contraceptive Use

\begin{tabular}{lc}
\hline Test statistics & Test results \\
\hline Lagrange Multiplier & 309.281 \\
Wald & 271.969 \\
Likelihood Ratio & 194.898 \\
\hline
\end{tabular}

The independent variables in the first variance equation, since they cause the heteroscedasticity and affect the same dependent variable or type of place of residence, region, number of living children, the current type of employment of woman and whether or not the partner is insured by health insurance.

The second dependent variable, the use of contraceptive methods in the second index equation, is affected by the type of place of residence, region, number of living children, the current type of employment of woman, total income in the household, whether or not the partner is insured by health insurance and partner's position at work.

The independent variables in the second variance equation, since they cause the heteroscedasticity and affect the same dependent variable are age, education level of woman and partner and woman's approval of the family planning.
If the significant coefficients in the index and variance equations are positive, this means that the variable is effective in increasing the probability of the occurrence of the relevant dependent variable. If it is negative, this means that the variable is effective in reducing the probability of the occurrence of the relevant dependent variable.

The hypothesis about the correlation between the error terms is tested. The results of the some wellknown test statistics for testing the hypothesis $\mathrm{H} 0$ : $\rho^{* *}=0$ are given in Table 3 which are significant at $\mathrm{a}=0.01$ significance level. The result shows that in the presence of heteroscedasticity, the two dependent variables must be examined together.

Another way to understand $\rho^{* *}$ is to think about other variables, both which cannot be taken to the model and which can affect each of the dependent variables. If $\hat{\rho} * *$ 's positive and statistically significant, this means that there is a positive and interactive correlation between those two dependent variables. That is also a proof in the sense of those two variables cannot be examined separately.

Regardless of whether we interpret $\hat{\rho} * *$ 's sign, is that a statistically significant relationship between the two dependent variables does exist. Models failing to account for this will produce incorrect estimates. 
American J. Applied Sci., 1 (4): 332-337, 2004

Table 4: Components of Marginal Effects for $\left(\mathrm{E}\left[\mathrm{y}_{1}=1 / \mathrm{y}_{2}=1\right]\right)(\%$ Change)

\begin{tabular}{|c|c|c|c|c|c|c|}
\hline Variable & Effect $x_{1}$ & Effect $x_{2}$ & Effect $\mathrm{z}_{1}$ & Effect $z_{2}$ & Total Effect & Standard Error \\
\hline Age & 0.06849 & 0.00000 & 0.00000 & 0.02079 & $0.08927 * * *$ & 0.01106 \\
\hline $\begin{array}{l}\text { Type of place on } \\
\text { residence }\end{array}$ & 0.00000 & -0.00329 & 0.05373 & 0.00000 & $0.05044 * * *$ & 0.01276 \\
\hline Region & 0.00000 & 0.00708 & -0.01522 & 0.00000 & $-0.00814 * *$ & 0.00415 \\
\hline $\begin{array}{l}\text { Education level of } \\
\text { woman }\end{array}$ & 0.00000 & 0.00000 & 0.01520 & -0.02224 & -0.00703 & 0.00976 \\
\hline $\begin{array}{l}\text { Number of living } \\
\text { children }\end{array}$ & 0.00000 & -0.01831 & 0.07185 & 0.00000 & $0.05353 * * *$ & 0.00482 \\
\hline $\begin{array}{l}\text { Current type of } \\
\text { employment of } \\
\text { woman }\end{array}$ & 0.00000 & -0.00372 & 0.01134 & 0.00000 & 0.00762 & 0.00545 \\
\hline $\begin{array}{l}\text { Total income in the } \\
\text { household }\end{array}$ & 0.03773 & -0.00594 & 0.00000 & 0.00000 & $0.03178^{* * * *}$ & 0.01170 \\
\hline $\begin{array}{l}\text { Education level of } \\
\text { partner }\end{array}$ & 0.01976 & 0.00000 & 0.00000 & -0.01105 & 0.00870 & 0.00919 \\
\hline $\begin{array}{l}\text { Partner insured by } \\
\text { health insurance }\end{array}$ & 0.00000 & -0.01203 & 0.03086 & 0.00000 & 0.01883 & 0.01159 \\
\hline $\begin{array}{l}\text { Knowledge of FP } \\
\text { methods of woman }\end{array}$ & -0.39319 & 0.00000 & 0.00000 & 0.00000 & $-0.39319 * * *$ & 0.03074 \\
\hline $\begin{array}{l}\text { Woman's approval } \\
\text { of FP }\end{array}$ & -0.06079 & 0.00000 & 0.00000 & -0.00488 & $-0.06566 * * *$ & 0.01959 \\
\hline $\begin{array}{l}\text { Partner's position at } \\
\text { work }\end{array}$ & 0.00000 & -0.00344 & 0.00225 & 0.00000 & -0.00118 & 0.00931 \\
\hline
\end{tabular}

Table 5: Components of Marginal Effects for $(E[y 2=1 / y 1=1])(\%$ Change)

\begin{tabular}{|c|c|c|c|c|c|c|}
\hline Variable & Effect x1 & Effect $x 2$ & Effect z1 & Effect z2 & Total effect & Standard Error \\
\hline Age & 0.00000 & -0.00510 & -0.03406 & 0.00000 & $-0.03916 * * *$ & 0.00434 \\
\hline Type of place of residence & 0.00539 & 0.00000 & 0.00000 & -0.00400 & 0.00138 & 0.00316 \\
\hline Region & -0.01160 & 0.00000 & 0.00000 & 0.00113 & $-0.01046 * * *$ & 0.00142 \\
\hline Education level of woman & 0.00000 & 0.00000 & 0.03644 & -0.00113 & $0.03530 * * *$ & 0.00432 \\
\hline Number of living children & 0.03001 & 0.00000 & 0.00000 & -0.00535 & $0.02465 * * *$ & 0.00289 \\
\hline $\begin{array}{l}\text { Current type of } \\
\text { employment of woman }\end{array}$ & 0.00609 & 0.00000 & 0.00000 & -0.00085 & $0.00524 * * *$ & 0.00141 \\
\hline $\begin{array}{l}\text { Total income in the } \\
\text { household }\end{array}$ & 0.00974 & -0.00281 & 0.00000 & 0.00000 & $0.00692 * *$ & 0.00273 \\
\hline Education level of partner & 0.00000 & -0.00147 & 0.01811 & 0.00000 & $0.01663 * * *$ & 0.00281 \\
\hline $\begin{array}{l}\text { Partner insured by health } \\
\text { insurance }\end{array}$ & 0.01971 & 0.00000 & 0.00000 & -0.00230 & $0.01741 * * *$ & 0.00367 \\
\hline $\begin{array}{l}\text { Knowledge of FP methods } \\
\text { of woman }\end{array}$ & 0.00000 & 0.02930 & 0.00000 & 0.00000 & $0.02930 * * *$ & 0.00269 \\
\hline Woman's approval of FP & 0.00000 & 0.00453 & 0.00800 & 0.00000 & $0.01252 * * *$ & 0.00339 \\
\hline Partner's position at work & 0.00564 & 0.00000 & 0.00000 & -0.00017 & $0.00547 * * *$ & 0.00188 \\
\hline
\end{tabular}

$*=\mathrm{p} \leq 0.10 ; * *=\mathrm{p} \leq 0.05 ; * * *=\mathrm{p} \leq 0.01$

Firstly, the effect of independent variables on the dependent variable can be seen from the sign of the coefficients. To determine the magnitude of those effects, marginal effects can be calculated. The marginal effects of the independent variables that can affect the induced abortion decision and the use of contraceptive method decision are given in Table 4 and 5. Definitions of the column labels given in Tables 4 and 5 are:

$\mathrm{x}_{1}$ effect: Independent variable's effect on the first index equation,

$\mathrm{x}_{2}$ effect: Independent variable's effect on the second index equation,

$\mathrm{z}_{1}$ effect: Independent variable's effect on the first variance equation,

$\mathrm{z}_{2}$ effect: Independent variable's effect on the second variance equation.

Total effect: The total of the four effects.
It can be seen easily from Table 4 , knowledge of FP methods, age, woman's approval of FP, number of living children, type of place of residence, total income in the household and region are the ordered significant variables according to the magnitude of the percentage of total effect which is affecting induced abortion when it is known that the woman used any contraceptive methods $\left(\mathrm{y}_{2}=1\right)$.

The marginal effect of the independent variable age indicates that an increase of one unit in age causes an increase on the probability of having an induced abortion. According to the magnitude of the percent of total effect, age is effective by about nine percent points in increasing the probability of having an induced abortion. The effect of the age in the variance equation is about $2 \%$ and positive. Both in the first equation and in the second variance equation variable age are effective in increasing the probability of having an induced abortion, when it is known that the woman 
used any contraceptive method. The other variable's marginal effect can be interpreted in the same way.

The results in Table 4 for $y_{2}=1$ is interpreted in the same way for $y_{1}=1$ in Table 5. Age is the most effective variable at using contraceptive methods when it is known that the woman had an induced abortion (0.03916). The other independent variables are education level of woman (0.03530), knowledge of FP methods of woman, number of living children, partner insured by health insurance, education level of partner, woman's approval of FP, region, total income in the household, partner's position at work and current type of employment of woman follow that.

It is concluded that the decision of married women's (15-49 age) induced abortion is affected by all other variables except for the education level of woman/partner and partner's position at work when significance levels $a=0.01,0.05$ or 0.10 are used. The decision to use contraceptive methods is affected by all the independent variables in the equation.

The results of the research showed that induced abortion is perceived and used as a contraceptive method among the women. This shows that it is the correct way to examine those two variables together.

\section{REFERENCES}

1. Hacettepe Institute of Population Studies (HIPS), 1999. 1998 Turkish Demographic and Health Survey (TDHS-98), Hacettepe University Institute of Population Studies and Macro International Inc., Ankara, Turkey.

2. Greene, W.H., 1997. Econometric Analysis. Prentice Hall International Inc., pp: 1-1075.

3. Desilva, S., 2000. Skills, Partnership and Tenancy in Sri Lankan Rice Farms. Economic Growth Center, Yale Univ., Center Discussion Paper No: 819.
4. Meng, C.L. and P. Schmidt, 1985. On the cost of partial observability in the bivariate probit model. Int. Econ. Rev., 26: 71-85.

5. Amemiya, T., 1976. The maximum likelihood, the minimum chi-square and the nonlinear weighted least-squares estimator in the general qualitative response model. J. American Statist. Assoc., Theory and Methods Sec., 71: 347-51.

6. Godfrey, L.E., 1997. Misspecification Tests in Econometrics: The Lagrange Multiplier Principle and Other Approaches. Econometric Society Monographs No: 16, Cambridge Univ. Press.

7. Judge, G., C. Hill, W. Griffiths and T. Lee, 1985. The Theory and Practice of Econometrics. New York, John Wiley and Sons Inc., pp: 1-810.

8. Harvey, A.C., 1976. Estimating regression models with multiplicative heteroscedasticity. Econometrica, 44: 461-65.

9. Just, R. and R. Pope, 1978. Stochastic specification of production functions and economic implications. J. Econometrics, 7: 67-86.

10. Yatchew, A.J. and Z. Grilliches, 1985. Specification error in probit models. Rev. Econ. Stat., 67: 134-39.

11. Engle, R.F., 1984. Wald Likelihood Ratio and Lagrange Multiplier Tests in Econometrics. Edited by Z. Grilliches, M.D. Intriligator. Handbook of Econometrics, Elsevier Science Publishers BV, 2: 776-826.

12. Greene, W.H., 1996. Marginal Effects in the Bivariate Probit Model. Working Paper Series EC96-11, New York Univ., pp: 1-6.

13. Ozarici, O., 2002. Bivariate probit model with full observability and heteroscedasticity and an application. Ph.D. Thesis. Osmangazi Univ., Turkey. 